\title{
Development of PV array configuration under different partial shading condition
}

\author{
Mohammad Syahir Bin Ishak, Rahmatul Hidayah Salimin, Ismail Musirin, Zulkiffli Abdul Hamid \\ Faculty of Electrical Engineering, Universiti Teknologi MARA, Malaysia
}

\begin{tabular}{l} 
Article Info \\
\hline Article history: \\
Received Sep 27, 2018 \\
Revised Jan 17, 2019 \\
Accepted Mar 4, 2019 \\
\hline Keywords: \\
Array configuration \\
Bridge-link \\
Partial shading \\
PV array \\
Total-cross-tied
\end{tabular}

\section{Corresponding Author:}

Mohammad Syahir bin Ishak, Faculty of Electrical Engineering, Universiti Teknologi MARA, 40450 Shah Alam, Malaysia. Email: syahirishak261@gmail.com

\begin{abstract}
This paper investigates the performances of different photovoltaic (PV) array under several shading condition. Four types of photovoltaic array configuration scheme which are 'Series' (S), Series-Parallel' (SP), Total-Cross-Tied' (TCT), and 'Bridge-Link' (BL) array topologies were tested by applying a $6 \times 6 \mathrm{PV}$ array under 6 different shading scenarios. The modeling is developed using Matlab/Simulink. The performances and output characteristics of photovoltaic array are compared and analyzed. System engineer can use the detailed characteristics of different array configuration to approximate the outcome power and pick the best configuration of the system by concerning the current natural condition to enhance the overall efficiency.
\end{abstract}

Copyright (c) 2019 Institute of Advanced Engineering and Science. All rights reserved.

\section{INTRODUCTION}

Growing interest of renewable energy sources and solar photovoltaic (PV) has become more significant to generate clean energy[1-4]. However it have some disadvantages which are low energy conversion performance, high initial cost of purchasing the solar system itself, and dependence of power output on weather or atmospheric condition [5-7]. The outputs of PV devices are non-linear due to its dependency to the environmental conditions such as solar irradiance and temperature [8].

There are numerous elements that make contributions to the reduction of output electricity from PV arrays. One of the main reasons that contribute the loss of output power is partial shading [9]. In large PV installation, the partial shading will reduce the efficiency of the overall system. It is impractical to keep away from the partial shading of the array in all weather conditions and seasons [10]. The output of PV module always depends on the solar irradiance and temperature. The solar energy can be change to electrical energy by using PV cell, module or array.

Several researchers have studied the consequences and explored the remedies of partial shading on PV systems. One of the best solutions in this direction is PV array configuration. Different PV array configurations that have been proposed in the literature are: Series (S), Parallel (P), Series-Parallel (SP), Total-Cross-Tied (TCT), Bridge-Linked (BL) and Honey-Comb (HC). In [11-13], a MATLAB-based modeling and simulation scheme suitable for studying the performance of the maximum output power generated.

In a normal condition, power - voltage (P-V) and current - voltage (I-V) curve will only have one peak value, whereas under partial shading condition (PSC) the curve will be multiple peaks. Therefore, the designer has to choose the right or suitable value and use the maximum power point tracking (MPPT) to track the maximum power [14-15]. MPPT is largely a dc-dc converter which makes use of an 
algorithm to determine the maximum power point (MPP) of the P-V and I-V characteristics in varying environmental situation [16-17].

In [18], generalized MATLAB M-code has been developed to suit with any required array size, configuration, shading patterns and number of bypass diodes. Modeling and comparison of the performance of different PV array configurations under various PSCs is presented [19]. The performance of existing and some proposed solar PV array configurations is investigated comprehensively in [20]. In [21], a full investigation of only Total-Cross-Tied (TCT) configuration under PSC is done neglecting other configurations. Interconnections whose performance lies in between SP and TCT interconnections are proposed in [22] to create a clear correlation between number and location of shaded modules, interconnections and maximum power obtained

In [23], reconfiguration of array has been made by way of converting connection of all modules on the array. The proposed circuit which is a combination of a buck-boost converter and the switched-capacitor (BBSC) circuits, equalizes the voltage of PV modules and prevents bypass diodes from bypassing the shaded modules in a string [24]. The author in [25] is proposed by using Binary Search Algorithm (BSA) to determine the maximum power point (MPP) in photovoltaic (PV) system under partial shaded conditions.

In this paper, 6 different shading case studies on 6 by $6 \mathrm{PV}$ array, the performance of Series (S), Series-Parallel (SP), Total-Cross-Tied (TCT), and Bridge-Link (BL) configurations were analyzed. Matlab/Simulink is used as a simulation tools to construct all PV array configurations under different shading cases. The comparisons of the performances of photovoltaic array configuration in terms of output power were made.

\section{RESEARCH METHOD}

\subsection{Structured of the photovoltaic array}

Analysis and comparisons of the output characteristic of PV array with S, SP, TCT and BL configurations were made in this study. The array consists of 36 photovoltaic modules in a $6 \times 6$ array arrangement and a PV module simulation model. Figure 1 shows the block diagrams of the photovoltaic module simulation model. The maximum power point, $\mathrm{P}_{\max }$, open-circuit voltage, $\mathrm{V}_{\mathrm{OC}}$, short-circuit current $\mathrm{I}_{\mathrm{SC}}$, voltage at the maximum point, $\mathrm{V}_{\mathrm{mp}}$ and current at the maximum point, $\mathrm{I}_{\mathrm{mp}}$. All of the parameters mentioned above are given under Standard Test Conditions (STC) in the manufacturer's datasheet.

The variant is justified by applying parameters of SunPower SPR-X20-250-BLK solar panel from datasheet. Parameters of solar PV module are shown in Table I.

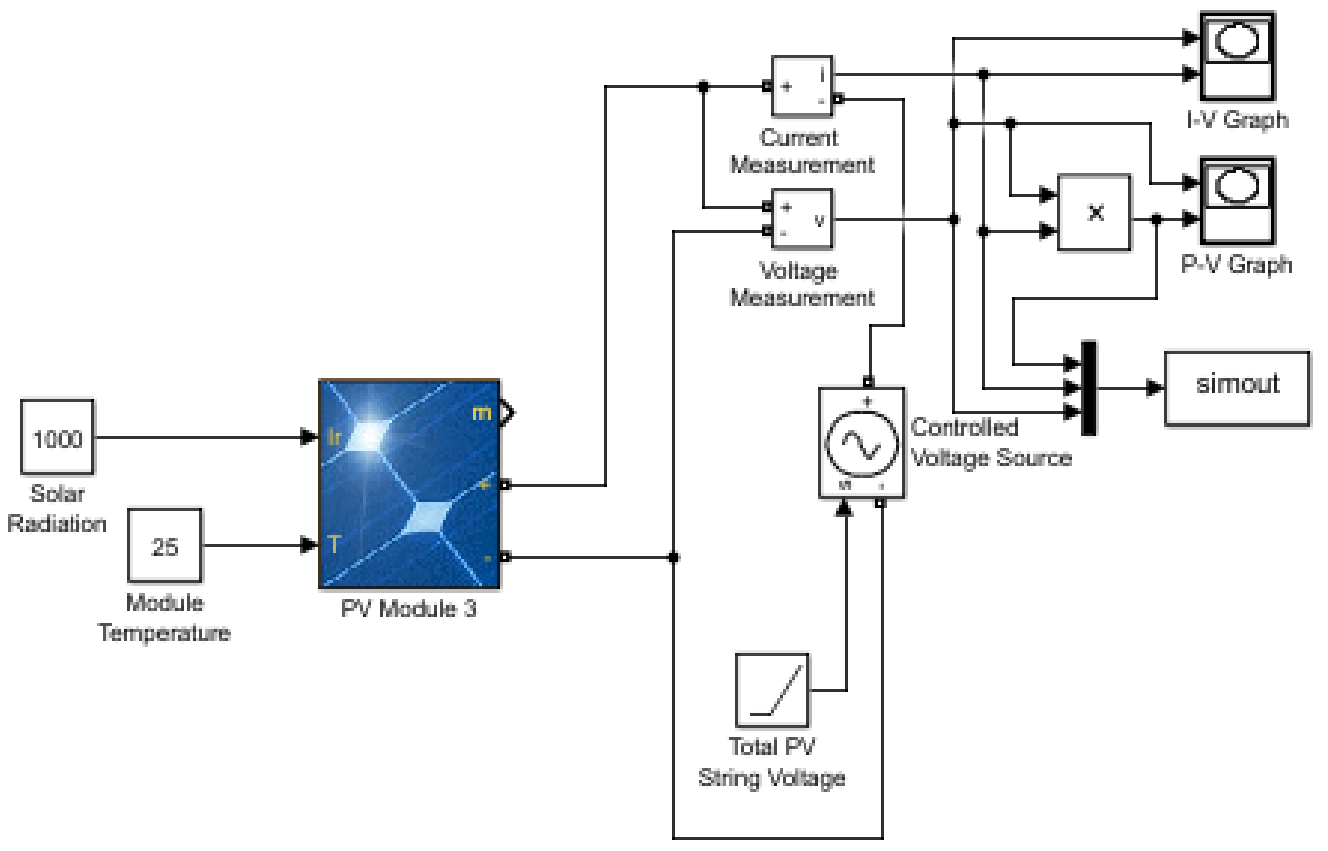

Figure 1. PV Module simulation model in Matlab/Simulink 
Table 1. The PV Module parameter

\begin{tabular}{ccr}
\hline Variables & Parameter & \multicolumn{1}{c}{ Value } \\
\hline Pmax & Maximum power & $250 \mathrm{~W}$ \\
Impp & Maximum power point current & $5.84 \mathrm{~A}$ \\
Vmpp & Maximum power point voltage & $42.8 \mathrm{~V}$ \\
$\mathrm{Isc}$ & Short circuit current & $50.9 \mathrm{~V}$ \\
Voc & Open circuit voltage & $50.9 \mathrm{~V}$ \\
$\mathrm{Kp}$ & Temperature coefficient of Pmpp & $-0.30 \% /{ }^{\circ} \mathrm{C}$ \\
$\mathrm{Kv}$ & Temperature coefficient of Voc & $-125.6 \mathrm{mV} /{ }^{\circ} \mathrm{C}$ \\
$\mathrm{Ki}$ & Temperature coefficient of Isc & $3.5 \mathrm{~mA} /{ }^{\circ} \mathrm{C}$ \\
$\mathrm{Ns}$ & Number of series cell & 72 \\
\hline
\end{tabular}

\subsection{I-V and $P-V$ characteristics of photovoltaic array under identical illumination}

The efficiency and maximum output power of PV module can be affected by the changing of solar irradiance value and temperature. The temperature that received by the solar panel is inversely proportional to the generated output power. For solar irradiance, it has almost linear effect on current and power and marginal effect on voltage. The Current-Voltage (I-V) and Power-Voltage (P-V) characteristics of PV module running at same temperature of $25^{\circ} \mathrm{C}$ and different of irradiance value are given in Figure 2 and Figure 3.

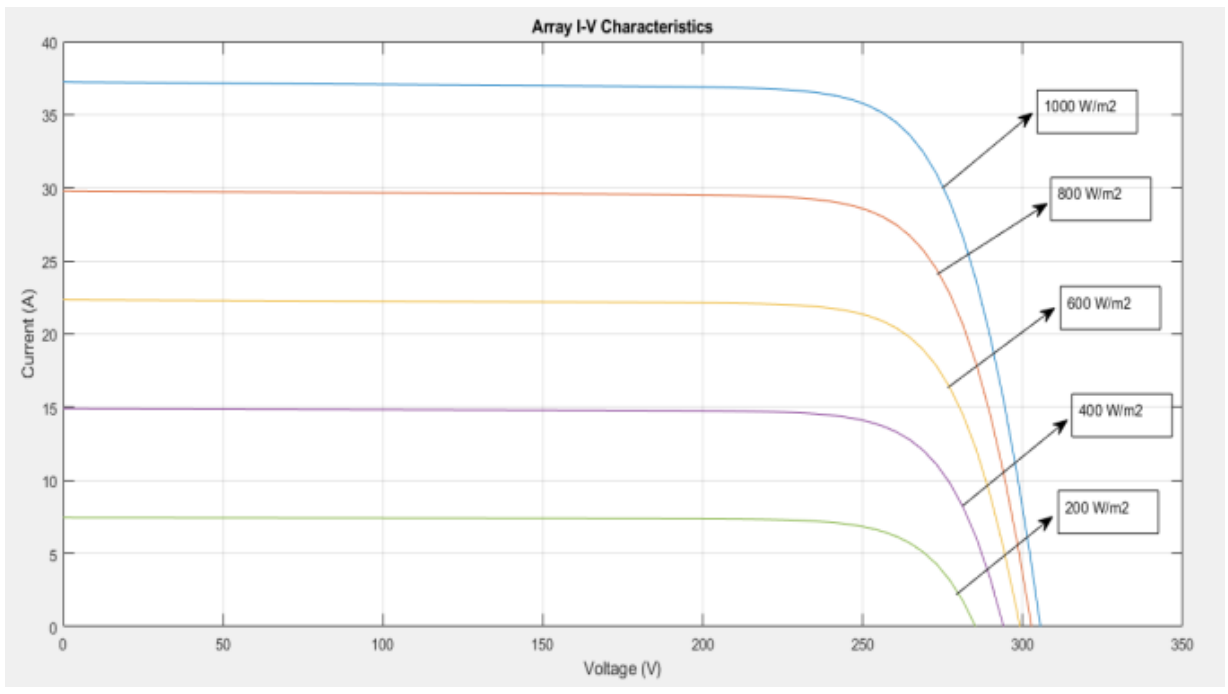

Figure 2. I-V Characteristics of simulated array with different irradiance value

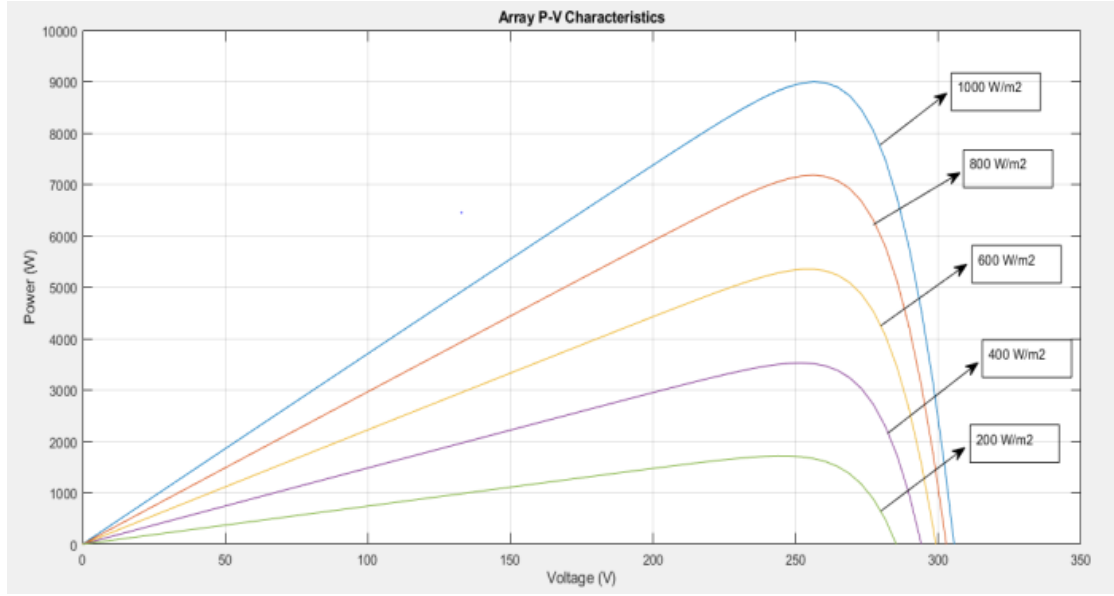

Figure 3. P-V Characteristics of simulated array with different irradiance value

Development of PV array configuration under different partial shading ... (Mohammad Syahir Bin Ishak) 


\subsection{PV array configuration}

PV Module is developed by joining several PV cell into one unit. Normally, a PV module consists of 36 cells that connected in series configuration, however other connection are also feasible. Figure 4 shows the connection of the PV Module in Series, Series-Parallel, Total-cross-tied and Bridge-link with 36 PV cells used in the simulation.

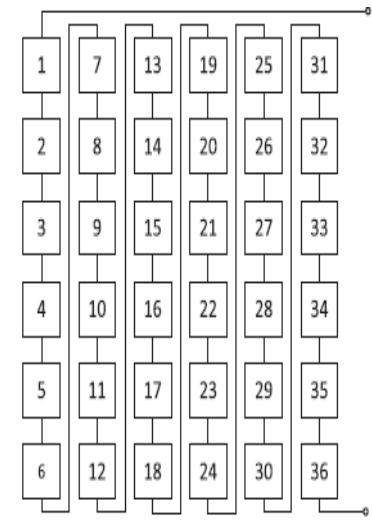

(a)Series

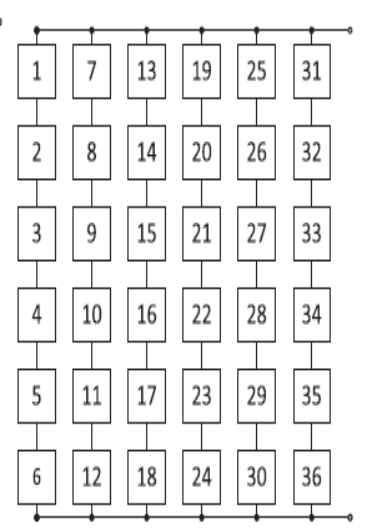

(b)Series-Parallel

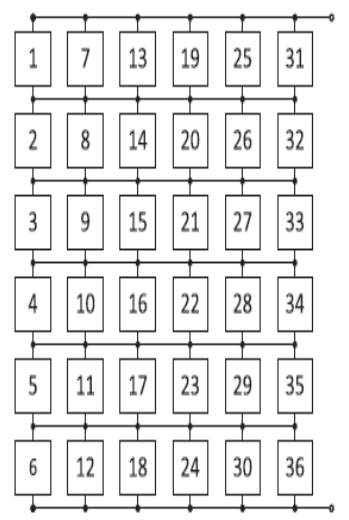

(c) Total-Cross-Tied

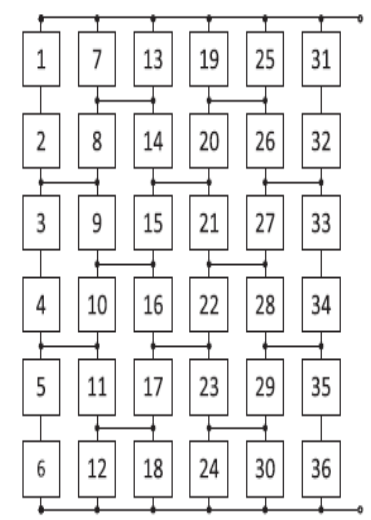

(d)Bridge-Link

Figure 4. Schematic diagram of $36 \mathrm{PV}$ arrays $(6 \times 6)$ in different configuration

\subsection{Modelling of partial shading effects}

This study focused to investigate and identify the performances of dissimilarity of array configuration under several shading condition or scenario. There are 6 different shading patterns which they are represented as the passage of a cloud over the PV array. There are 3 different irradiance value in each pattern which are $1000 \mathrm{~W} / \mathrm{m} 2,500 \mathrm{~W} / \mathrm{m} 2$, and $200 \mathrm{~W} / \mathrm{m} 2$ to represent the fully illumination condition, half clear cloud and most dimness of cloud focus. The shading scenario can be described according to:

- $\quad$ First Shading Scenario: The value of solar irradiance that set for 4 modules that located at left bottom of the array are $200 \mathrm{~W} / \mathrm{m} 2$ while 12 modules that irradiated with $500 \mathrm{~W} / \mathrm{m} 2$ and remaining 20 modules fully received light with $1000 \mathrm{~W} / \mathrm{m} 2$.

- Second Shading Scenario: The value of solar irradiance that set for two row at the bottom of the array are $200 \mathrm{~W} / \mathrm{m} 2$. This has covered 12 modules while two rows at the middle of the array are partly shaded with $500 \mathrm{~W} / \mathrm{m} 2$ and remaining two rows at the top of the array are fully irradiated with $1000 \mathrm{~W} / \mathrm{m} 2$.

- Third Shading Scenario: The value of solar irradiance that set for two columns at the right side of the array is $200 \mathrm{~W} / \mathrm{m} 2$. This has covered 12 modules while two columns at the middle of the array are partly shaded with $500 \mathrm{~W} / \mathrm{m} 2$ and remaining two columns at the left side of the array are fully irradiated with $1000 \mathrm{~W} / \mathrm{m} 2$.

- Fourth Shading Scenario: The value of solar irradiance that set for two rows at the top of the array are $200 \mathrm{~W} / \mathrm{m} 2$. This has covered 12 modules while two rows at the middle of the array are partly shaded with $500 \mathrm{~W} / \mathrm{m} 2$ and remaining two rows at the bottom of the array are fully irradiated with $1000 \mathrm{~W} / \mathrm{m} 2$.

- $\quad$ Fifth Shading Scenario: The value of solar irradiance that set for 4 modules at the middle of the array are $200 \mathrm{~W} / \mathrm{m} 2$ while 12 modules are partly shaded with $500 \mathrm{~W} / \mathrm{m} 2$ and remaining 20 modules received light with $1000 \mathrm{~W} / \mathrm{m} 2$.

- Sixth Shading Scenario: The value of solar irradiance that set for 4 modules at the middle of the array are $1000 \mathrm{~W} / \mathrm{m} 2$ while 12 modules are partly shaded with $500 \mathrm{~W} / \mathrm{m} 2$ and remaining 20 modules received light with $200 \mathrm{~W} / \mathrm{m} 2$.

\section{RESULTS AND ANALYSIS}

The simulation are executed by using Matlab/Simulink software. All the configurations namely Series, Series-Parallel, Total-Cross-Tied, and Bridge-Link are compared in term of their disapearance output power under partial shading condition (PSC). The comparison is analyzed by based on the different irradiance value and shading scenario. Figure 5 shows Power-Voltage characteristics of the mentioned array configuration under 6 partial shading scenarios.

Int J Pow Elec \& Dri Syst Vol. 10, No. 3, Sep 2019 : $1263-1269$ 
Based on Table 2, the maximum output power in the case shading scenario 1, 5, and 6 for TCT is higher compared with the other three of PV array configuration. Meanwhile, based on Table IV, V and VI show the maximum output power in the case shading 2, 3, and 4 for TCT, BL and SP produced the same maximum output power if compared with $\mathrm{S}$ configuration that produced least output power.

Table 2. Maximum output power for shading scenario 1-6

\begin{tabular}{|c|c|c|c|c|}
\hline \multirow{2}{*}{ Configuration } & \multicolumn{2}{|c|}{ Scenario 1} & \multicolumn{2}{|c|}{ Senario 4} \\
\hline & $P \max (W)$ & Number of peaks & $\operatorname{Pmax}(\mathrm{W})$ & Number of peaks \\
\hline Series & $480,531,330$ & 3 & $2355,2038,330$ & 3 \\
\hline Series-Parallel & $2957,4407,5193$ & 3 & $2877,3183,1983$ & 3 \\
\hline Total-Cross-Tied & $2878,4202,5470$ & 3 & $2877,3183,1983$ & 3 \\
\hline Bridge-Link & $2900,4302,5310$ & 3 & $2877,3183,1983$ & 3 \\
\hline \multirow{2}{*}{ Configuration } & \multicolumn{2}{|c|}{ Scenario 2} & \multicolumn{2}{|c|}{ Scenario 5} \\
\hline & $\operatorname{Pmax}(\mathrm{W})$ & Number of peaks & $\operatorname{Pmax}(\mathrm{W})$ & Number of peaks \\
\hline Series & $480,530,330$ & 3 & 1500 & 1 \\
\hline Series-Parallel & $2877,3183,1983$ & 3 & $2957,4407,5193$ & 3 \\
\hline Total-Cross-Tied & $2877,3183,1983$ & 3 & $2878,4202,5470$ & 3 \\
\hline Bridge-Link & $2877,3183,1983$ & 3 & $2878,4267,5382$ & 3 \\
\hline \multirow{2}{*}{ Configuration } & \multicolumn{2}{|c|}{ Scenario 3} & \multicolumn{2}{|c|}{ Scenario 6} \\
\hline & $\operatorname{Pmax}(\mathrm{W})$ & Number of peaks & $\operatorname{Pmax}(\mathrm{W})$ & Number of peaks \\
\hline Series & 1500 & 1 & $1155,1343,286$ & 3 \\
\hline Series-Parallel & 5036 & 1 & $1685,2441,1817$ & 3 \\
\hline Total-Cross-Tied & 5036 & 1 & $1610,2477,1946$ & 3 \\
\hline Bridge-Link & 5036 & 1 & $1635,2436,1937$ & 3 \\
\hline
\end{tabular}

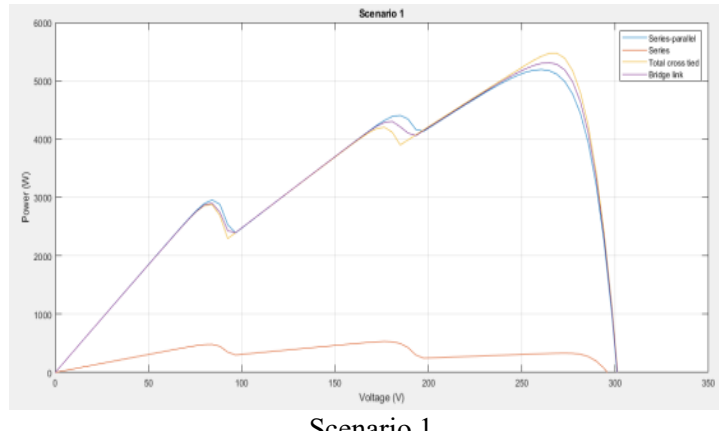

Scenario 1

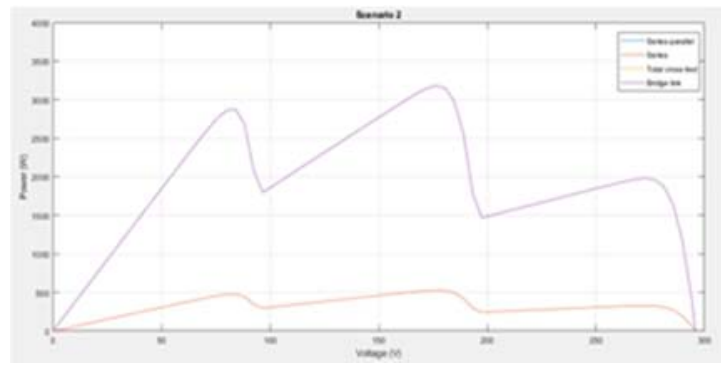

Scenario 2

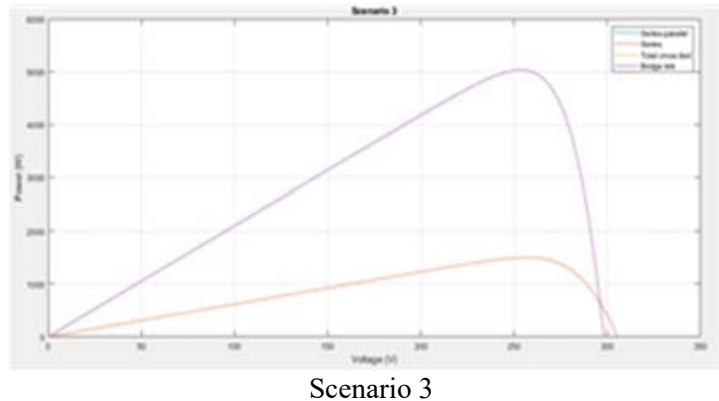

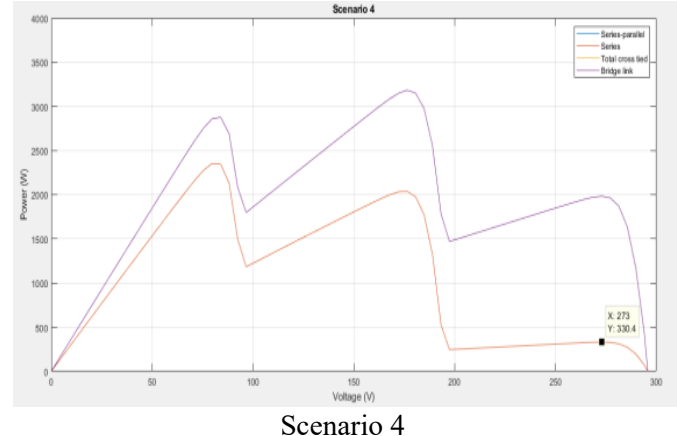

Scenario 4

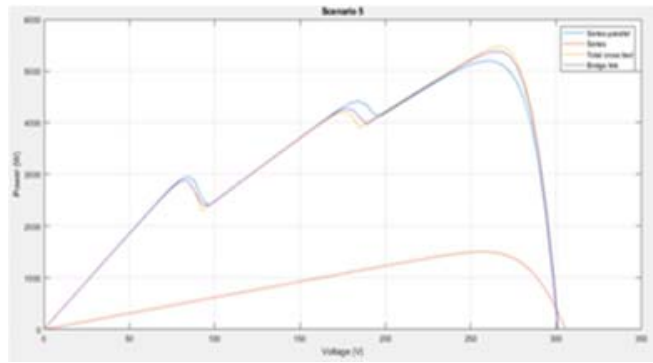

Scenario 5

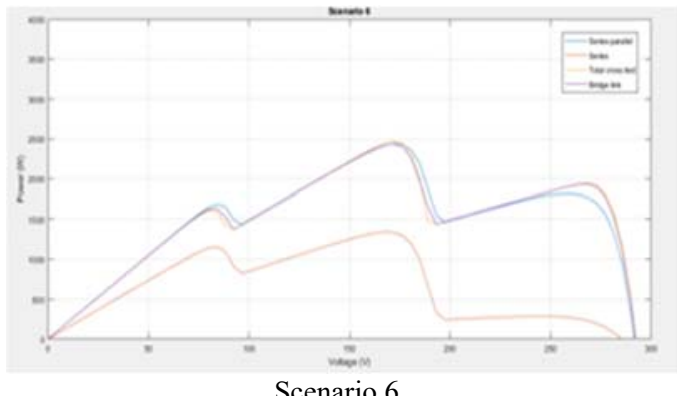

Scenario 6

Figure 5. P-V characteristics of 4 different photovoltaic array configurations in 6 different scenario

Development of PV array configuration under different partial shading ... (Mohammad Syahir Bin Ishak) 
From the result, it shows the Total-Cross-Tied setting has shown the greatest performance in every partial shading scenario and it can be considered that even though its pattern is complex, it is beneficial with the presence of extra-complicated shading scenario in actual surroundings or practical state.

\section{CONCLUSION}

In the study, a simulation technique is used for analyzing PV modules with four different of photovoltaic array configuration which are Series, Series-Parallel, Total-Cross-Tied and Bridge-Link configurations respectively by using Matlab/Simulink software. The assessment of four connection configurations has been done through using $36 \mathrm{PV}$ modules and evaluating in terms of their maximum output power for four configuration schemes. The effect of partial shading to the PV modules on the Series, SeriesParallel, Total-Cross-Tied and Bridge-Link configurations also have been investigated under 6 different shading scenarios. Referring to these results, Total-Cross-Tied configuration the highest maximum output power even though under partial shading conditions compared to other configurations. As a result, PV array configuration strongly affecting the efficiency of PV array. The result that offer or provide is very beneficial and trustworthy details on the performances of array configuration in different shading situation or scenario. All the information can be used to enhance whole efficiency of the photovoltaic system during design the system.

\section{ACKNOWLEDGEMENTS}

The authors would like to acknowledge the Institute of Research Management and Innovation (IRMI), UiTM Shah Alam, Selangor, Malaysia for the financial support of this research. This research is supported by Research Management and Innovation (IRMI), UiTM with project code: 600-IRMI/MYRA 5/3/BESTARI (027/2017).

\section{REFERENCES}

[1] L. F. L. Villa, D. Picault, B. Raison, S. Bacha, and A. Labonne, "Maximizing the power output of partially shaded photovoltaic plants through optimization of the interconnections among its modules," IEEE J. Photovoltaics, vol. 2, no. 2, pp. 154-163, 2012.

[2] H. S. Sahu and S. K. Nayak, "Power enhancement of partially shaded PV array by using a novel approach for shade dispersion," 2014 IEEE Innov. Smart Grid Technol. - Asia, ISGT ASIA 2014, pp. 498-503, 2014.

[3] Asif, Muhammad, and Tariq Muneer. "Energy supply, its demand and security issues for developed and emerging economies." Renewable and Sustainable Energy Reviews, vol. 11, no. 7, pp. 1388-1413, 2007.

[4] Wang, Y-J., and P-C. Hsu. "Analytical modelling of partial shading and different orientation of photovoltaic modules." IET Renewable Power Generation, vol. 4, no. 3, 272-282, 2010.

[5] Mäki, Anssi, and Seppo Valkealahti. "Power losses in long string and parallel-connected short strings of seriesconnected silicon-based photovoltaic modules due to partial shading conditions." IEEE Transactions on Energy Conversion, vol. 27, pp. 1, 173-183, 2012.

[6] Ishaque, Kashif, and Zainal Salam. "A review of maximum power point tracking techniques of PV system for uniform insolation and partial shading condition." Renewable and Sustainable Energy Reviews, vol. 19, pp.475-488, 2013.

[7] Ma, Tao, Hongxing Yang, and Lin Lu. "Development of a model to simulate the performance characteristics of crystalline silicon photovoltaic modules/strings/arrays." Solar Energy, vol. 100, pp. 31-41G, 2014.

[8] Y.-J. Wang and P.-C. Hsu, "Analytical modelling of partial shading and different orientation of photovoltaic modules," IET Renewable Power Generation, vol. 4, no. 3, p. 272, 2010.

[9] S. Bana and R. P. Saini, "Experimental investigation on power output of different photovoltaic array configurations under uniform and partial shading scenarios," Energy, vol. 127, pp. 438-453, 2017.

[10] K. Ş. Parlak, "PV array reconfiguration method under partial shading conditions," Int. J. Electr. Power Energy Syst., vol. 63, pp. 713-721, 2014.

[11] Mohammadnejad, Shahram, Ali Khalafi, and S. Morteza Ahmadi. "Mathematical analysis of total-cross-tied photovoltaic array under partial shading condition and its comparison with other configurations." Solar Energy, vol. 133, 501-511, 2016.

[12] Maghami, Mohammad Reza, et al. "Power loss due to soiling on solar panel: A review," Renewable and Sustainable Energy Reviews, vol. 59, pp. 1307-1316, 2016.

[13] M. G. Villalva, J. R. Gazoli, and E. Ruppert Filho, "Modeling and circuit-based simulation of photovoltaic arrays," 2009 Brazilian Power Electron. Conf. COBEP2009, pp. 1244-1254, 2009.

[14] Silvestre, Santiago, Alfredo Boronat, and A. Chouder. "Study of bypass diodes configuration on PV modules." Applied Energy, vol. 86, no. 9, 1632-1640, 2009.

Int J Pow Elec \& Dri Syst Vol. 10, No. 3, Sep 2019 : 1263 - 1269 
[15] Tey, Kok Soon, and Saad Mekhilef. "Modified incremental conductance algorithm for photovoltaic system under partial shading conditions and load variation," IEEE Transactions on Industrial Electronics. vol. 61, no. 10, pp. 5384-5392, 2014.

[16] Wang, Jen-Cheng, et al. "A novel multipoint direct-estimation method for the maximum power point tracking of photovoltaic modules under partially shaded irradiation conditions." Energy Conference and Exhibition (ENERGYCON), 2012 IEEE International. IEEE, 2012.

[17] Belhachat, F., and C. Larbes. "Modeling, analysis and comparison of solar photovoltaic array configurations under partial shading conditions." Solar Energy, vol. 120, pp. 399-418, 2015.

[18] Parlak, Koray Şener. "PV array reconfiguration method under partial shading conditions." International Journal of Electrical Power \& Energy Systems, vol. 63, 713-721, 2014.

[19] Seyedmahmoudian, Mohammadmehdi, et al. "Simulation and hardware implementation of new maximum power point tracking technique for partially shaded PV system using hybrid DEPSO method." IEEE transactions on sustainable energy, vol. 6, no. 3, 850-862, 2015.

[20] Dadjé, Abdouramani, et al. "Maximum power point tracking methods for photovoltaic systems operating under partially shaded or rapidly variable insolation conditions: a review paper." International Journal of Sustainable Engineering, vol. 9, no. 4, pp. 224-239, 2016.

[21] La Manna, Damiano, et al. "Reconfigurable electrical interconnection strategies for photovoltaic arrays: A review." Renewable and Sustainable Energy Reviews, vol. 33, pp. 412-426, 2014.

[22] Karatepe, Engin, Mutlu Boztepe, and Metin Colak. "Development of a suitable model for characterizing photovoltaic arrays with shaded solar cells." Solar Energy, vol. 81, no. 8, 977-992, 2007.

[23] G. Velasco-Quesada, F. Guinjoan-Gispert, R. Piqué-López, M. Román-Lumbreras, and A. Conesa-Roca, "Electrical PV array reconfiguration strategy for energy extraction improvement in grid-connected PV systems," IEEE Trans. Ind. Electron., vol. 56, no. 11, pp. 4319-4331, 2009.

[24] M. Tahmasbi-Fard, M. Tarafdar-Hagh, S. Pourpayam, and A. Haghrah, "A Voltage Equalizer Circuit to Reduce Partial Shading Effect in Photovoltaic String," IEEE J. Photovoltaics, pp. 1-8, 2018.

[25] H. et Al., "Binary Search Algorithm as Maximum Power Point Tracking for Photovoltaic System Under Partial Shaded Condition." 